\title{
Memoria y enseñanza de la Historia ${ }^{1}$ Joaquim PRATS CUEVAS
}

Universitat de Barcelona

jprats@ub.edu

La irrupción de la llamada memoria histórica, como debate social, ha sido un fenómeno muy general en todos aquellos países que han vivido un periodo de dictaduras, de guerras internas, de represión y episodios sangrientos. Este debate ha llegado al mundo de la educación generando una discusión de cómo debe tratarse este fenómeno en las clases de historia de las enseñanzas escolares.

Vivimos ciertamente tiempos de euforia presentista. Hace tan sólo unos años repetíamos a nuestros alumnos que la historia es el estudio del pasado para la comprensión y explicación del presente y la previsión o transformación del futuro. Ha pasado mucha agua por el río de la historia en poco tiempo y esta ha perdido por el camino sus buenas intenciones, diagnósticas del presente y pronósticas del futuro. Ha muerto el historiador-profeta y, en cambio, goza de muy buena salud el político-historiador que instrumentaliza la historia en función de sus paradigmas presentes.

Creo que era Borges quien decía que la memoria es como un saco de espejos rotos. La memoria personal se constituye en fragmentos emotivos que seleccionan lo que se quiere recordar y borran, en ocasiones totalmente, aquello que se desea olvidar. Ninguno de los fragmentos refleja el conjunto de la realidad pasada y, en ocasiones, la desfiguran. Si es así la memoria individual, qué decir de la memoria colectiva, la llamada Memoria Histórica a la que, algunos, quieren dar carta de naturaleza en los contenidos curriculares de algunas etapas educativas.

De hecho, hay pensadores que la reivindican para combatir las manipulaciones que se cometen en la escritura de «historias oficiales» institucionalizadas. Es cierto que hay olvidos que son usados para ciertos fines de ocultación de las represiones de las dictaduras y que sirven a los que, de manera interesada, han defendido los perdones y amnistías que han seguido a los grandes crímenes al siglo XX. Son estrategias que propugnan el «olvido feliz». En estos casos sí que es aceptable, como dice Ricoeur, un «uso inteligente del recuerdo y de la memoria social como medio para la liberación». Pero el problema de la memoria va más allá de recordar o no. Todos tienen derecho a recuperar su pasado, pero no hay razón para erigir el culto a la memoria por la memoria; sacralizar la memoria es otro modo de hacerla estéril.

Se puede aceptar que la recuperación de la memoria social puede tener claras funciones de saneamiento de las sociedades que han sufrido traumas históricos. Puede ser educativo incorporar al alumnado en procesos que suponen renunciar al «olvido» interesado. Pero no debe confundirse este tipo de actividades, que pueden tener sentido en la formación de la conciencia social, con la provechosa enseñanza de la historia como ciencia social.
La controversia científica se centra en la distinción que debe realizarse entre memoria e historia. La memoria histórica es un proceso estrictamente individual, biográfico, y que, por tanto, no puede ser tildada de conocimiento histórico más que por metonimia. Memoria e historia tienen poco que ver entre sí, aunque solamente fuese por escala. La historia de «buenos y malos», de «víctimas y verdugos» puede servir como mero argumentario para reafirmar ideas políticas, incluso para entender una parte de nuestro presente, y fijar nuestro compromiso. Pero no contribuye a la aceptación y a la comprensión.

Para que la llamada memoria histórica llegue a ser provechosa e inspiradora de aprendizajes, el requisito fundamental es que sea verificada y pensada a través de la historia. De hecho, la historia [científica] es una trituradora de memoria que la digiere para poder producir conocimiento. La trituración de las memorias no se produce por la distancia en el tiempo, sino por la aplicación de método y teoría histórica sobre el recuerdo, el vestigio o la fuente. Nunca los hechos fueron realmente como se recuerdan.

La memoria histórica es en realidad un combustible para la caldera de la historia, ya que si la historia solo fuese memoria, ya no sería historia. Para serlo debe combinar los planos individuales, épicos y personales etc., con planos, sociales, temporales e incluso seculares. Trabajar la memoria histórica con los estudiantes plantea a los profesores un reto de gran interés didáctico: la combinación de lo micro y lo macro considerados holísticamente, lo que supone que una escala y una parte no se explican sin las otras. Por lo tanto, lo recordado no se podrá explicar por sí solo, y lo concreto, las memorias, serán plurales y contrastadas. Pero, hay que insistir, no explicaran nada por sí mismas.

Por todo lo señalado, a pesar de las propuestas memorialísticas, que se enmarcan en el debate político, en campañas contra un juez que pretende restituir la dignidad de las víctimas de la Guerra Civil, o en la fuerte presencia de estas cuestiones en los debates mediáticos, se debe mantener una prudente distancia y autonomía relativa en la enseñanza con estos temas, tan potentes, como contingentes. Además, me atrevo a afirmar que los currículos y la mayoría de los libros que utiliza el alumnado de ESO y Bachillerato contienen explicaciones de gran rigor y cientificidad, también de los hechos dramáticos de nuestra historia reciente. Hay que recuperar la potencia de la racionalidad de la materia histórica (con mayúsculas) como contenido fundamental de la educación. Sobre todo, porque el conocimiento de la historia es mucho más transformador y revolucionario que recrearse en los recuerdos o las memorias de unos contra los otros. 